\title{
Cutaneous vasculitis in lupus treated with IV immunoglobulin
}

\author{
Matheo Augusto Morandi Stumpf ${ }^{1}$ [D $\cdot$ Carla Romagnolli Quintino ${ }^{1} \cdot$ \\ Marcelo Arlindo Vasconcelos Miranda Rodrigues ${ }^{1} \cdot$ Fernando Peixoto Ferraz de Campos $^{1} \cdot$ Celina Wakisaka Maruta $^{2}$
}

Received: 5 January 2021 / Revised: 1 February 2021 / Accepted: 4 February 2021 / Published online: 23 February 2021

(C) International League of Associations for Rheumatology (ILAR) 2021

\section{Presentation}

A 44-year-old man presented to the emergency department with a 3-week history of painful ulcers in the sacral region with a new skin rash. He had received an early diagnosis of systemic lupus erythematosus (SLE) at the age of 7 years and was using only prednisone $15 \mathrm{mg}$ daily (he had stopped using hydroxychloroquine by himself 3 months earlier). On physical examination, multiple necrotic ulcers were noted with major livedo racemosa intermingled (Fig. 1a). The systemic examination was unremarkable. A differential diagnosis workup between vasculitis and antiphospholipid syndrome was performed, and a skin biopsy was promptly collected.

Histopathologic examination revealed diffuse neutrophilic infiltrate around small vessels (Fig. 1c). Direct immunofluorescence showed moderate homogeneous deposits of both immunoglobulin M (Fig. 1d) and C3 (Fig. 1e) along the basement membrane zone.

Laboratory tests revealed hemoglobin $11.8 \mathrm{~g} / \mathrm{dL}$; an elevated erythrocyte sedimentation rate of $47 \mathrm{~mm}$, C-reactive protein $10 \mathrm{mg} / \mathrm{dL}$, creatinine $1 \mathrm{mg} / \mathrm{dL}$, urea 30 $\mathrm{mg} / \mathrm{dL}$, cryoglobulin negative, low $\mathrm{C} 3$ of $39 \mathrm{mg} / \mathrm{dL}$ and $\mathrm{C} 4$ of $8 \mathrm{mg} / \mathrm{dL}$, ANCA and serology tests for HIV, hepatitis B and $\mathrm{C}$, and VDRL were negative, ANA 1/640 nuclear homogeneous, anti-Smith $>180 \mathrm{IU} / \mathrm{mL}$, anti-SSA > $240 \mathrm{IU} /$

Matheo Augusto Morandi Stumpf

matheoaugusto@hotmail.com

1 Internal Medicine Department, University of São Paulo (USP), Av. Prof Lineu Prestes, 2565, Butantã, São Paulo CEP: 05508-000, Brazil

2 Dermatology Department, University of São Paulo (USP), São Paulo, Brazil
$\mathrm{mL}$, anti-SSB $>320 \mathrm{IU} / \mathrm{mL}$, anti-dsDNA $>379 \mathrm{IU} / \mathrm{mL}$, negative anti-phospholipid antibodies (anti-cardiolipin, anti-beta 2 glycoprotein I, and lupus anticoagulant), urinalysis without significant proteinuria; and no dysmorphic erythrocytes.

We opted to start prednisone $1 \mathrm{mg} / \mathrm{kg}$ daily with hydroxychloroquine $400 \mathrm{mg} /$ day, and an improvement in the livedo was observed. However, the patient's ulcers became infected during the hospital stay (Fig. 1b), demonstrated by a positive culture for Pseudomonas aeruginosa, and they were treated with culture-guided ciprofloxacin and surgical debridement. Due to clinical instability from sepsis, a second immunosuppressive agent was reconsidered, and we chose to start immunoglobulin $1 \mathrm{~g} / \mathrm{kg}$ for two consecutive days. Unfortunately, soon after, the patient died from septic shock.

\section{Discussion}

Cutaneous vasculitis may be seen in 19-28\% of patients with SLE and accounts for $89 \%$ of vasculitis cases in this disease [1]. Male sex, young-onset SLE, disease duration, presence of livedo reticularis, hematological parameters (anemia and high erythrocyte sedimentation rate), anti-dsDNA, anti-SSA [2], anti-SSB, and anti-Smith are the most common parameters associated with cutaneous vasculitis in SLE patients [3].

Histopathology is characterized by small-vessel neutrophilic vasculitis, and under immunofluorescence, deposits of $\operatorname{IgG}$, IgM, and $\mathrm{C} 3$ at the dermo-epidermal junction are common (lupus band test) [4]. However, it is important to evaluate both laboratory and clinical profile of the patient since lupus band test could be found in bullous pemphigoid, porphyrias, rosacea, skin infections and even in healthy sun-exposed skin [5]. 
Fig. 1 a Livedo racemosa and necrotic ulcers at admission. $\mathbf{b}$ Lesion aspect after infection due to Pseudomonas aeruginosa. c Perivascular inflammatory infiltrate composed of neutrophils (hematoxylin and eosin $\times 400$ ). d Direct immunofluorescence showing moderate homogeneous deposits of IgM along the dermoepidermal junction (lupus band test) (fluorescein isothiocyanate, $\times 100)$. e Direct immunofluorescence showing moderate homogeneous deposits of $\mathrm{C} 3$ along the dermo-epidermal junction (lupus band test) (fluorescein isothiocyanate, $\times 200)$

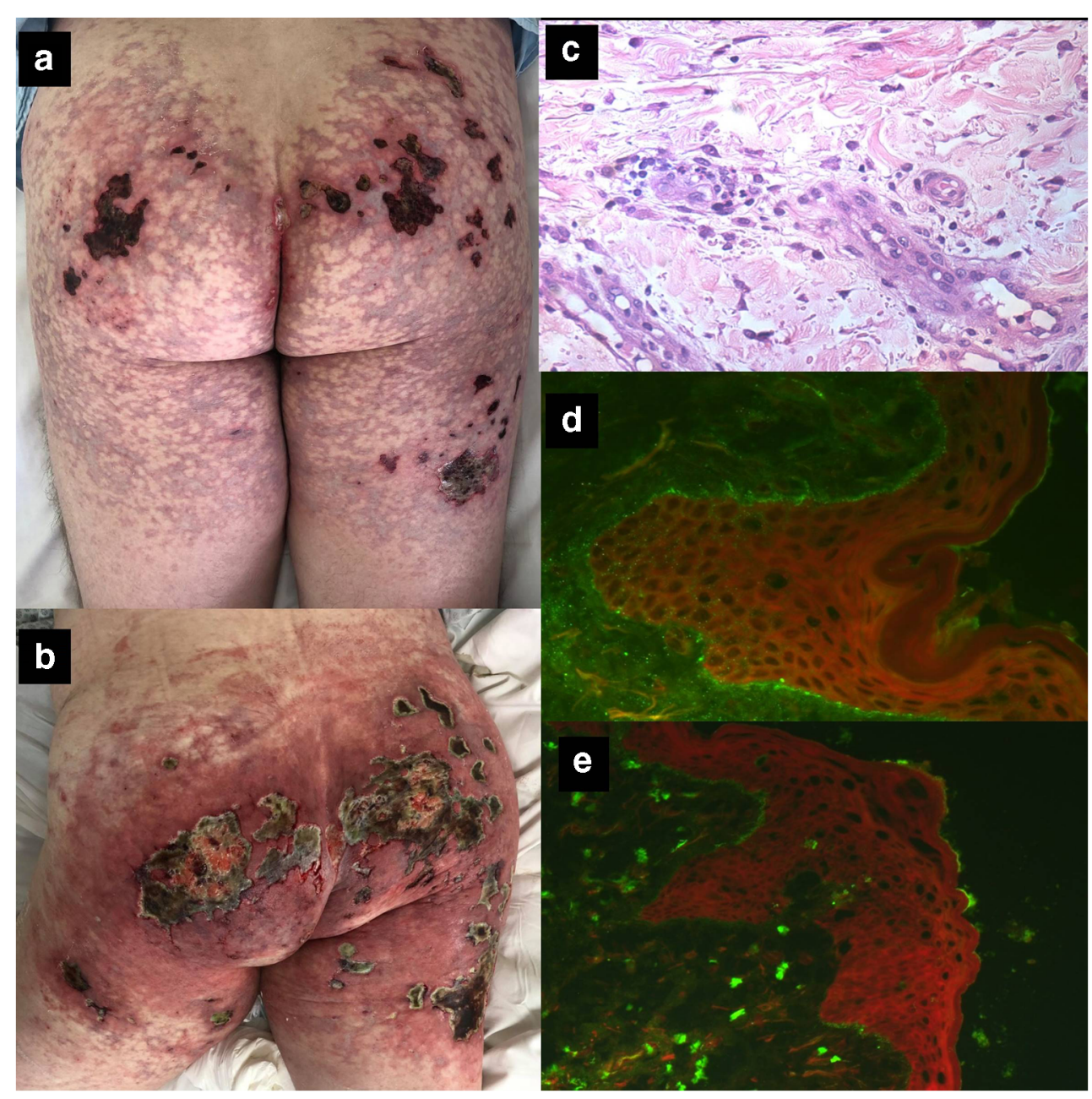

Antimalarials, thalidomide and dapsone are treatment options for cutaneous vasculitis in lupus. For resistant cases immunoglobulin could be an option. The usual dose is $1 \mathrm{~g} / \mathrm{kg}$ for 2 consecutive days followed by $400 \mathrm{mg} / \mathrm{kg}$ monthly until disease resolution or for 6 months [6]. The use of immunoglobulin is considered off-label since there is a lack of randomized controlled trials, but it is an excellent option, particularly in unstable patients who cannot tolerate another immunosuppressant drug.

Funding This study was not funded by any company.

\section{Declarations}

Conflict of interest The authors have nothing to disclose. The authors declare that they have no conflict of interest.

Ethics approval and consent to participate Written informed consent was obtained from the patient for publishing this material.

\section{References}

1. Calle-Botero E, Abril A (2020) Lupus vasculitis. Curr Rheumatol Rep 22(10):71

2. Kallas R, Goldman D, Petri MA (2020) Cutaneous vasculitis in SLE. Lupus Sci Med 7(1):e000411

3. Fukuda MV, Lo SC, de Almeida CS, Shinjo SK (2009) Anti-Ro antibody and cutaneous vasculitis in systemic lupus erythematosus. Clin Rheumatol 28(3):301-304

4. Alberti-Violetti S, Berti E, Marzano AV (2018) Cutaneous and systemic vasculitides in dermatology: a histological perspective. G Ital Dermatol Venereol 153(2):185-193

5. Reich A, Marcinow K, Bialynicki-Birula R (2011) The lupus band test in systemic lupus erythematosus patients. Ther Clin Risk Manag $7: 27-32$

6. Goodfield M, Davison K, Bowden K (2004) Intravenous immunoglobulin (IVIg) for therapy-resistant cutaneous lupus erythematosus (LE). J Dermatolog Treat 15(1):46-50

Publisher's note Springer Nature remains neutral with regard to jurisdictional claims in published maps and institutional affiliations. 